\title{
Parâmetros e métodos adotados no regulamento de etiquetagem da eficiência energética de edifícios - parte 1: método prescritivo
}

Parameters and methods adopted in the energy eficiency
regulation for buildings -part 1: prescriptive method

\section{Joyce Correna Carlo Roberto Lamberts}

\section{Resumo}

Joyce Correna Carlo Departamento de Arquitetura e Universidade Federal de Viçosa Avenida Peter Henry Rolfs, $\mathrm{s} / \mathrm{n}$ Viçosa - MG - Brasil CEP $36570-000$ Tel.: (31) 3899-1982 Email: joycecarlo@ufv.br

Roberto Lamberts Laboratório de Eficiência Energética em Edificações, Departamento de Engenharia

Universidade Federal de Santa

Catarina

Cx. Postal 476

Florianópolis - SC - Brasil CEP 88040-900

Tel.: (48) 3721-5184

lamberts@labeee.ufsc

Recebido em 06/01/2010

Aceito em 14/05/2010

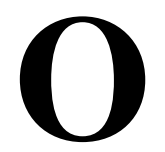

Regulamento Técnico da Qualidade do Nível de Eficiência Energética de Edifícios Comerciais, de Serviços e Públicos foi publicado no Brasil em fevereiro de 2009 como parte do Programa Brasileiro de Etiquetagem do INMETRO. Contém dois métodos de avaliação: o método prescritivo e o método de simulação. Neste artigo, o método prescritivo é rapidamente descrito para que seus fundamentos sejam discutidos, indicando especificidades e aplicações do método. É apresentada a aplicação deste método em um edifício existente, considerando 13 alternativas para a determinação dos níveis de eficiência da envoltória, sistema de iluminação e sistema de condicionamento de ar. Mostrou-se os casos nos quais o método de simulação é mais indicado que o prescritivo, por limitações deste último - os resultados variaram de níveis de eficiência A, mais elevados, a E, de baixa eficiência. Dessa forma, mostrou-se o potencial de avaliação do método prescritivo.

Palavras-chave: Eficiência energética. Etiquetagem. Prescritivo.

\section{Abstract}

The Technical Regulations for Energy Efficiency Labelling of Commercial Buildings (RTQ-C) was published in Brazil in February 2009 as part of INMETRO Brazilian Labeling Program. It contains two evaluation methods: the prescriptive method and the simulation method. This paper describes the prescriptive method, and discusses its foundation, pointing out specific features and applications of this method. This method was applied in an existing building, considering 13 alternatives to access the energy efficient labels of the envelope, lighting system and air conditioning system. The paper points out cases in which the simulation method is more appropriated than the prescriptive method, due to limitations of the later - the results ranged from A, more efficient, to E, less efficient. Then, this analysis indicates the evaluation potential of the prescriptive method.

Keywords: Energy efficiency. Labelling. Prescriptive method. 


\section{Introdução}

A certificação energética de edifícios é uma tendência mundial, já adotada por diversos países e em desenvolvimento por outros. Em Portugal, o Regulamento das Características de Comportamento Térmico dos Edifícios (RCCTE) e o Regulamento dos Sistemas Energéticos de Climatização em Edifícios (RSECE) indicam os níveis de desempenho de edifícios e edifícios climatizados respectivamente (DIRECÇÃO GERAL DE ENERGIA, 2002; PORTUGAL, 2006). A Austrália avalia seus edifícios com parâmetros diferenciados por região ou cidade, mas todos referenciam o Building Code of Australia (ABCB, 2004). Nos EUA, as normas de eficiência são usadas há cerca de 30 anos e já houve adaptação progressiva da indústria construtiva aos padrões de eficiência. A Norma 90.1 (ASHRAE, 2007), norma dos EUA para edificações eficientes envolvendo todas as atividades não industriais exceto as residenciais unifamiliares, é um exemplo de uma norma cujos protótipos para simulação foram baseados em um levantamento nacional de edificações que possui atualização quinquenal (CBECS, 2003).

O Brasil junta-se a esse grupo com a participação do Inmetro e do Programa Brasileiro de Etiquetagem (PBE), que lançou o Regulamento Técnico da Qualidade do Nível de Eficiência Energética de Edifícios Comerciais, de Serviços e Públicos (RTQ-C) (BRASIL, 2009a) em fevereiro de 2009, estabelecendo os parâmetros para a definição do nível de eficiência de um edifício e posterior fornecimento da Etiqueta Nacional de Conservação de Energia (ENCE). Essa iniciativa vem atender à Lei $\mathrm{n}^{\mathbf{0}} 10.295$, a primeira lei de eficiência energética no Brasil, que dispõe sobre a Política Nacional de Conservação e Uso Racional de Energia (BRASIL, 2001b) e que foi regulamentada pelo Decreto $\mathrm{n}^{\circ} 4.059$, de 19 de outubro de 2001 (BRASIL, 2001a). Esse decreto estabeleceu a criação de "níveis máximos de consumo de energia, ou mínimos de eficiência energética, de máquinas e aparelhos consumidores de energia fabricados ou comercializados no país, bem como as edificações construídas", assim como a necessidade de "indicadores técnicos e regulamentação específica", para estabelecer a obrigatoriedade dos níveis de eficiência no país. O Decreto criou o "Comitê Gestor de Indicadores e Níveis de Eficiência Energética - CGIEE" e, especificamente para edificações, o "Grupo Técnico para Eficientização de Energia nas Edificações no País", para propor uma forma de regulamentar as edificações construídas no Brasil, visando ao uso racional da energia elétrica (BRASIL, 2001a).
O desempenho do edifício e sua necessidade de normalização foram inicialmente discutidos em 1991, em um encontro nacional (CHICHIERCHIO; FROTA, 1991; LAMBERTS, 1991), o que resultou nas normas da ABNT atualmente vigentes: NBR 15220 (ABNT, 2005) e NBR 15575 (ABNT, 2008). A primeira norma apresenta requisitos referentes ao desempenho térmico como métodos de cálculo e de medição de propriedades térmicas de componentes, enquanto a segunda abrange outros tópicos além do desempenho térmico, como estruturas e sistemas hidrossanitários. Entretanto, nenhuma apresenta parâmetros ou requisitos visando diretamente à eficiência energética da edificação, além de referenciarem somente edificações residenciais. ${ }^{1}$ Assim, a resposta direta à demanda nacional reconhecida pela Lei $n^{\circ} 10.295$ (BRASIL, 2001b) em gerar mecanismos de avaliação da eficiência energética de equipamentos e edificações foi a inclusão dos edifícios comerciais, de serviços e públicos no Programa Brasileiro de Etiquetagem do Inmetro, e a futura inclusão das edificações residenciais.

O RTQ-C (BRASIL, 2009a) foi publicado em 2009 em sua primeira versão para aplicação voluntária. Por ser novo no país, o mercado construtivo ainda terá de se adaptar ao conceito de eficiência de um edifício: os arquitetos, com os parâmetros de projeto; os profissionais envolvidos, com a construção civil com o registro de informações e documentos ao longo da obra; os fornecedores de materiais, com a uniformização da linguagem e parâmetros de especificação técnica de seus produtos; as agências financiadoras da construção, com os próprios conceitos de eficiência; e o público em geral, com a etiqueta de eficiência e seu significado (Etiqueta Nacional de Conservação de Energia - ENCE). Essa necessidade de adaptação exige simplificações e generalizações na primeira versão do regulamento, sendo alterações nos métodos de aplicação e nas restrições gradativas reservadas para as próximas versões. Isso não significa que o RTQ-C é brando, mas que não abrange todos os temas que participam da eficiência energética de um edifício. Diversos sistemas foram incluídos como bonificações, o que os tornam opcionais; orientação do edifício não foi considerada (mas o foram as fachadas), as proteções solares não são diferenciadas por fachada, condicionamento

\footnotetext{
${ }^{1}$ Embora a NBR 15220 apresente métodos de cálculo e medição referentes a materiais e propriedades térmicas para aplicação em qualquer tipo de edificação, indica características de edificações (paredes, janelas e coberturas) apenas para edificações residenciais de baixa renda.
} 
radiante e outros sistemas não possuem classificação prescritiva. Versões futuras do RTQ$\mathrm{C}$ poderão incluir gradativamente outros parâmetros ou sistemas cuja complexidade da avaliação será maior, mas em um momento em que os atores envolvidos com a construção civil, incluindo o consumidor e/ou o usuário, estejam familiarizados com os parâmetros atuais.

Deve-se também destacar a necessidade de desenvolvimento de parâmetros técnicos que permitam a correta especificação de materiais e componentes construtivos, de acordo com o exigido para a etiquetagem das edificações. A primeira iniciativa nesse sentido partiu de um acordo de cooperação técnica negociado entre Procel e Associação Técnica Brasileira das Indústrias Automáticas de Vidro (Abividro), com o intermédio do LabEEE/UFSC, a fim de criar o comprometimento em uniformizar métodos de determinação das propriedades térmicas e luminosas de seus produtos, até que normas técnicas nacionais sejam desenvolvidas. Esse acordo deverá ainda se estender a associações de fabricantes de outros produtos, a fim de viabilizar a documentação necessária à etiquetagem.

O RTQ-C está publicado (BRASIL, 2009a), assim como seu Regulamento de Avaliação da Conformidade (RAC-C) (BRASIL, 2009b) e o Manual de Aplicação do RTQ-C e RAC-C (PROCEL, 2009). O Regulamento Técnico da Qualidade do Nível de Eficiência Energética de Edificações Residenciais está em desenvolvimento, restando ainda o desenvolvimento do Regulamento de Avaliação da Conformidade do Nível Eficiência Energética de Edificações Residenciais (RAC-R) e seu manual.

Este artigo apresenta os recursos de cálculo do RTQ-C aplicados ao método prescritivo, suas potencialidades e as limitações que levam ao método de simulação. Não cabe a este artigo transcrever o conteúdo do Regulamento, mas sim discutir alguns critérios adotados no desenvolvimento de seus parâmetros, a partir da aplicação em alguns modelos de edifícios, todos baseados em um edifício real de Florianópolis. Dessa forma, o método descrito é resumido visando a uma compreensão geral do Regulamento. Mais informações acerca do conteúdo e dos métodos de cálculo podem ser encontradas no RTQ-C (BRASIL, 2009a) e em seu manual (PROCEL, 2009). Incluem-se nessas informações as definições, ilustrações explicativas e exemplos de cálculo das variáveis das equações.

As conclusões deste artigo levam a outro artigo, "Parâmetros e métodos adotados no regulamento de etiquetagem da eficiência energética de edifícios - parte 2: método de simulação”, que dá continuidade à análise, apresentando as particularidades deste outro método. Dessa forma, a aplicação do regulamento é apresentada em seu todo, com as limitações e potencialidades exemplificadas em um edifício-base.

\section{Normas e certificações}

Há dois tipos de políticas que podem ser implementadas visando ao uso racional da energia: políticas baseadas na limitação do nível de eficiência permitido mediante o estabelecimento de índices de desempenho mínimos; e as que estabelecem classificações por meio de programas de certificação. A eficiência mínima é, em geral, obrigatória e tem caráter prescritivo, com limites de desempenho estabelecidos por indicadores. Já a certificação é um mecanismo de mercado que visa promover a eficiência energética de uma edificação de elevado desempenho ao compará-la ao mínimo obrigatório (CASALS, 2006).

Além desses, atualmente fala-se em ratting, cuja tradução pode ser relacionada à classificação em si, que estabelece a qualidade energética de um edifício (PÉREZ-LOMBARD et al., 2009). Nesse caso, Rey, Velasco e Varela (2007) apresentaram um novo método de desenvolvimento de uma classificação energética para a Espanha, tendo identificado cinco passos: identificação do clima e obtenção dos dados climáticos; obtenção dos dados do edifício; obtenção das informações referentes aos sistemas de condicionamento; obtenção dos custos da energia e dos investimentos iniciais; e avaliação da iluminação. Com esses dados, calculam-se as cargas térmicas, as variações sazonais, os custos da energia e o nível de eficiência do edifício. Entretanto, como em outras propostas de certificação europeia (PORTUGAL, 2006; STANKEVICIUS; KARBAUSKAITE; MONSTVILAS, 2007), a eficiência energética está desvinculada do conforto do usuário, visto que as avaliações envolvem apenas o condicionamento artificial e supõem-se que os níveis de conforto já são atendidos em ambientes condicionados artificialmente.

Embora esse aspecto seja válido para países localizados em climas rigorosos, climas amenos como o brasileiro devem se valer das condições naturais exteriores que são desejadas nos ambientes internos. O regulamento de Singapura avalia apenas edifícios de escritórios condicionados cuja área condicionada mínima seja de $50 \%$ da área total, e estes $50 \%$ devem se equivaler a um mínimo de $1.000 \mathrm{~m}^{2}$. Mas o regulamento estabelece intervalos de temperatura e limites de umidade e velocidade do ar no ambiente 
interno, a fim de identificar se o sistema de climatização atende às necessidades de conforto. Esses itens são também estendidos aos níveis de iluminação (EANG; PRIYADARSINI, 2008).

A norma chinesa recomenda ainda parâmetros internos de projeto de condicionamento de ar, mas não são obrigatórios. Embora a China tenha uma zona climática temperada e uma quente e úmida, também se resume aos critérios para condicionamento de ar em seus edifícios públicos, que são equivalentes aos edifícios comerciais, de serviços e públicos de países capitalistas (HONG, 2009). Com base na Norma 90.1 da ASHRAE (2007), seu método prescritivo determina limites de área de aberturas envidraçadas, transmitância térmica de componentes opacos e densidade de potência de iluminação. Para o sistema de condicionamento de ar, indica limites de eficiência para resfriadores de líquido, como COP (coeficient of performance), para carga total, e IPLV (integrated part load value), para carga parcial.

Esse modelo é seguido em vários países que se baseiam nas normas da ASHRAE, com grande destaque para os sistemas de condicionamento por aquecimento e ventilação mecânica. A Norma 90.1 da ASHRAE (2007) ainda estabelece requisitos para motores e aquecimento de água. Apresenta três métodos de avaliação, pelo método prescritivo, por simulação e por um método de compensações, em que alguns requisitos podem ser compensados pela inserção de outros mais rigorosos (trade-offs).

Foi observando o desenvolvimento de normas e regulamentos em eficiência energética desenvolvidos em diversos países que PérezLombard et al. (2009) indicaram os sete passos que devem ser compreendidos para o estabelecimento de certificações energéticas. Em parte, eles sistematizam as questões levantas por Ollofsson, Meier e Lamberts (2004) sobre os critérios de avaliação de edifícios. Os passos de Pérez-Lombard et al. (2009) podem ser entendidos como perguntas sobre o que deve ser avaliado, como avaliar, como estabelecer os limites para os níveis de eficiência, a que o edifício deve ser comparado, como estabelecer a classificação, que melhoramentos recomendar e que informações o certificado de eficiência energética deve conter. Essas questões e outras mais específicas do RTQ-C são discutidas ao longo deste artigo, com especial atenção à envoltória do edifício, mostrando terem sido parte do desenvolvimento do Regulamento Técnico da Qualidade do Nível
Eficiência Energética de Edifícios Comerciais, de Serviços e Públicos (BRASIL, 2009a).

\section{Metodologia - parte 1: 0 conteúdo do RTQ-C}

\section{Métodos de determinação da eficiência}

Respondendo ao item levantado por PérezLombard et al. (2009) sobre como avaliar a eficiência de um edifício, o RTQ-C apresenta dois métodos para a determinação da eficiência: método prescritivo e método de simulação. O método prescritivo consiste em uma série de parâmetros predefinidos ou a calcular que indicam a eficiência do sistema. $\mathrm{O}$ método de simulação define parâmetros para modelagem e simulação, mas permite mais flexibilidade na concepção do edifício. É importante frisar que o método prescritivo foi estabelecido como um conjunto de regras gerais para identificar a eficiência do edifício e aplica-se à grande maioria de tipologias construídas atualmente no país. No entanto, ela não abrange todas as soluções possíveis de existir em um edifício, e muitos casos só poderão ser avaliados pela simulação. Esta, por sua vez, pode incluir soluções que promovem a eficiência energética e que não foram incluídas no método prescritivo, como aproveitamento da luz natural ou uso de tubos enterrados para climatização artificial.

A equação geral de classificação da eficiência, Equação 2.1 do RTQ-C (Equação 1), é aplicável ao método prescritivo. Apresenta pesos de $30 \%$ para envoltória, $30 \%$ para o sistema de iluminação e $40 \%$ para envoltória, que são aplicados em equivalentes numéricos (EqNum) da eficiência de cada sistema: EqNumEnv para envoltória, EqNumCA para condicionamento de ar e EqNumDPI para o sistema de iluminação. Sabe-se que nem sempre o edifício é comercializado contendo os sistemas de iluminação e condicionamento de ar instalados. Portanto, além da Etiqueta Nacional de Conservação de Energia (Ence) para o edifício completo (Figura 1), o regulamento possibilita o uso de etiquetas parciais para avaliações posteriores dos sistemas de iluminação e condicionamento. Na Figura 2, vê-se um modelo de Ence parcial para um edifício em que somente a envoltória e a iluminação foram etiquetadas. 


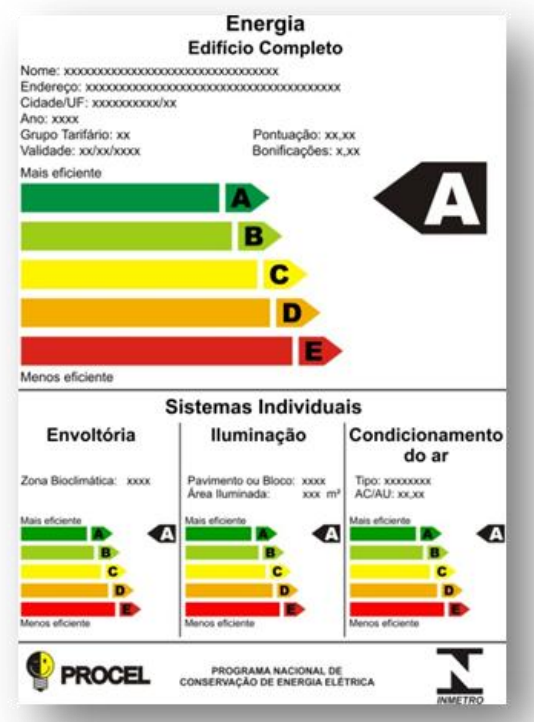

Figura 1 - Modelo da Etiqueta Nacional de Conservação de Energia (Ence)

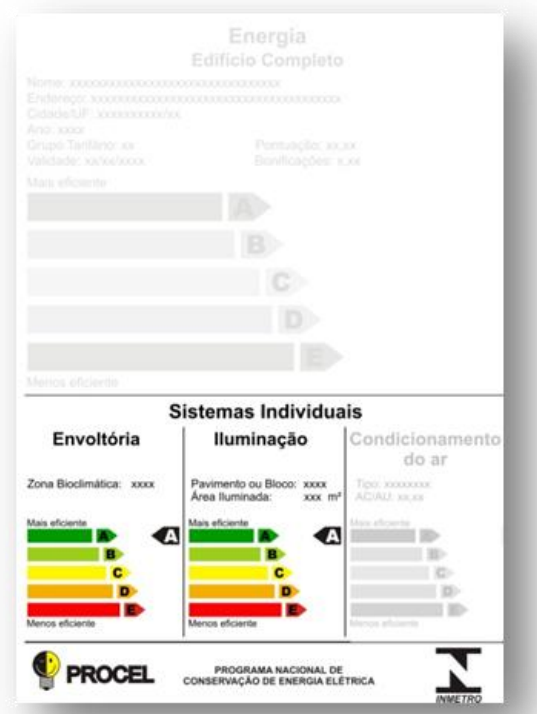

Figura 2 - Modelo da Ence parcial da envoltória e do sistema de iluminação

Além desses sistemas, deve-se citar a ventilação natural e as bonificações presentes na Equação 1.

$$
\begin{aligned}
& \text { PT }=0,30 \cdot\left\{\left(\text { EqNumEnv. } \frac{\mathrm{AC}}{\mathrm{AU}}\right)+\left(\frac{\mathrm{APT}}{\mathrm{AU}} \cdot 5+\frac{\mathrm{ANC}}{\mathrm{AU}} \cdot \text { EqNumV }\right)\right\} \\
& +0,30 \cdot(\text { EqNumDPI })+0,40 . \\
& \left\{\left(\text { EqNumCA. } \frac{\mathrm{AC}}{\mathrm{AU}}\right)+\left(\frac{\mathrm{APT}}{\mathrm{AU}} \cdot 5+\frac{\mathrm{ANC}}{\mathrm{AU}} \cdot \text { EqNumV }\right)\right\}+b_{0}^{1} \text { Eq. } 1
\end{aligned}
$$

Onde:

PT é a pontuação final que irá indicar o nível de eficiência do edifício;
EqNumEnv é o equivalente numérico da envoltória;

EqNumDPI é o equivalente numérico do sistema de iluminação, identificado pela sigla DPI, de densidade de potência de iluminação;

EqNumCA é o equivalente numérico do sistema de condicionamento de ar;

EqNumV é o equivalente numérico de ambientes não condicionados e/ou ventilados naturalmente;

APT é a área de piso dos ambientes de permanência transitória, desde que não condicionados;

ANC é a área de piso dos ambientes não condicionados de permanência prolongada; 
AC é a área de piso dos ambientes condicionados;

AU é a área útil; e

b é a pontuação obtida pelas bonificações, que varia de 0 a 1.

A ventilação natural é um parâmetro de correção do nível de eficiência energética para edifícios que oferecem condições adequadas de conforto sem precisar de condicionamento artificial. Ela está presente nas parcelas de condicionamento de ar e da envoltória sob a forma de um equivalente numérico (EqNumV). Quanto maior a área de ambientes naturalmente ventilados com conforto, menor é a participação do nível de eficiência do condicionamento de ar no equacionamento geral da eficiência do edifício, embora a eficiência desta última já tenha sido "transmitida" ao EqNumV (quanto melhor a envoltória, melhores são as condições de conforto no edifício). Mas o EqNumV só é obtido por meio de simulação. A complexidade da ventilação não permitiu o desenvolvimento de regras gerais para caracterizar os níveis de conforto e exigiu, assim, que a simulação se tornasse parte de uma equação do método prescritivo para esse caso específico.

Já as bonificações consistem em um máximo de 1 ponto adicional ao nível de eficiência do edifício, que pode ser obtido através de economias comprovadas por cálculo ou simulação. Essas economias podem ser no consumo de água ou eletricidade, sendo este último dividido em energias renováveis, cogeração ou qualquer tipo de inovação que promova a eficiência energética. Há percentuais anuais mínimos de economias que devem ser alcançados (20\% para água, $10 \%$ para energias renováveis, $30 \%$ para cogeração e inovações), mas a pontuação é proporcional ao percentual obtido. Assim, se o aproveitamento da luz natural for simulado e se for alcançada uma economia de $15 \%$ no consumo anual do edifício devido ao sistema de iluminação artificial, a bonificação será de 0,5 ponto. Se o mesmo edifício apresentar projeto hidráulico cuja memória de cálculo comprove uma economia no consumo anual de água de $10 \%$, a bonificação será de 1 ponto. Essa bonificação máxima terá sido obtida por meio de dois sistemas (iluminação e água) e de dois métodos de comprovação (simulação e memória de cálculo).

A simulação é aplicável para qualquer tipo de edifício, sendo ou não passível de avaliação pelo método prescritivo. No entanto, o método prescritivo é menos oneroso, e recomenda-se a simulação quando a simplicidade do método prescritivo não descreve apropriadamente as características do edifício que participam da eficiência energética. Assim, além da ventilação natural, são casos indicados para simulação: proteções solares projetadas para algum caso específico, como proteções com aletas que reflitam a luz para dentro do ambiente, grandes áreas envidraçadas com vidros de elevado desempenho térmico e luminoso, sistemas de condicionamento não previstos como pisos radiantes $\mathrm{e}$ especificidades do projeto de condicionamento de ar, como opções de automação ou resfriamento evaporativo.

\section{Método prescritivo: envoltória}

O item envoltória é composto de pré-requisitos para as aberturas zenitais e componentes opacos. As equações da envoltória referem-se às aberturas verticais envidraçadas e estão relacionadas à volumetria do edifício. A Equação 2 é um exemplo de uma das equações para análise da envoltória. Esta, especificamente, refere-se a edifícios cuja área de projeção é maior que $500 \mathrm{~m}^{2}$ e que estejam localizados na Zona Bioclimática 2 ou 3 (CARLO, 2008; CARLO; LAMBERTS, 2008).

$I C_{e n v}=-14,14 \cdot F A-113,94 \cdot F F+50,82 \cdot P A F_{T}+$ 4,86.FS - 0,32.AVS + 0,26.AHS - 35,75/FF0,54.PAF $T . A H S+277,98$

Eq. 2

Onde: ${ }^{2}$

IC é o indicador de consumo (adimensional);

$\mathrm{A}_{\mathrm{pe}}$ é a área de projeção do edifício $\left(\mathrm{m}^{2}\right)$;

$\mathrm{A}_{\mathrm{pcob}}$ é a Área de projeção da cobertura $\left(\mathrm{m}^{2}\right)$;

$\mathrm{A}_{\text {tot }}$ é a área total de piso $\left(\mathrm{m}^{2}\right)$;

$\mathrm{A}_{\mathrm{env}}$ é a área da envoltória $\left(\mathrm{m}^{2}\right)$;

AVS é o ângulo vertical de sombreamento, entre 0 e $45^{\circ}$ (graus);

AHS é o ângulo horizontal de sombreamento, entre 0 e $45^{\circ}$ (graus);

FF $\left(\mathrm{A}_{\mathrm{env}} / \mathrm{V}_{\mathrm{tot}}\right)$ é o fator de forma;

FA $\left(\mathrm{A}_{\mathrm{pcob}} / \mathrm{A}_{\mathrm{tot}}\right)$ é o fator altura;

FS é o fator solar;

$\mathrm{PAF}_{\mathrm{T}}$ é o percentual de abertura na fachada total (adimensional, para uso na equação); e

$\mathrm{V}_{\text {tot }}$ é o volume total da edificação $\left(\mathrm{m}^{3}\right)$.

Deve-se destacar ainda o $\mathrm{PAF}_{\mathrm{O}}$, referente ao percentual de abertura na fachada oeste. Caso o $\mathrm{PAF}_{\mathrm{O}}$ seja maior que o $\mathrm{PAF}_{\mathrm{T}}+0,20 . \mathrm{PAF}_{\mathrm{T}}$, devese adotar $\mathrm{PAF}_{\mathrm{O}}$ na Equação 2 em todos os campos onde se lê $\mathrm{PAF}_{\mathrm{T}}$.

Através dessa equação, calculam-se três indicadores de consumo:

\footnotetext{
${ }^{2}$ As definições com exemplos de cálculo e ilustrações das variáveis das equações de cálculo do IC estão presentes no RTQ-C (BRASIL, 2009a) e em seu manual (PROCEL, 2009).
} 
(a) $\mathrm{IC}_{\text {env }}$ : indicador de consumo de envoltória do edifício em avaliação;

(b) $\mathrm{IC}_{\min }$ : indicador de consumo mínimo, referente a características tabeladas no RTQ-C que são consideradas de uma envoltória eficiente, elaboradas a partir de um levantamento de campo (CARLO, 2008); e

(c) $\mathrm{IC}_{\max }$ : indicador de consumo máximo do nível de eficiência $\mathrm{D}$, referente a características tabeladas no RTQ-C que são consideradas típicas de uma envoltória de grande ocorrência nos edifícios comerciais, públicos e de serviços, identificadas a partir de um levantamento de campo (CARLO, 2008).

Todos os três indicadores acima apresentam o mesmo fator de forma e fator altura. $\mathrm{IC}_{\min }$ e $\mathrm{IC}_{\operatorname{maxD}}$ são subtraídos e divididos em quatro intervalos, a fim de identificar os limites do IC que definem os níveis de eficiência energética para aquela volumetria. Em seguida, deve-se verificar onde o $\mathrm{IC}_{\text {env }}$ está localizado nesses intervalos: o nível de eficiência da envoltória é dado pela localização do IC da envoltória.

A Figura 3 apresenta a posição dos indicadores de consumo na escala que define os demais limites. Deve-se notar que os níveis $\mathrm{A}$ e E não apresentam limites finais: o $\mathrm{IC}_{\min }$ é descartado após encontrados os intervalos, pois há outros edifícios mais eficientes que esse limite, cujo fim será apenas o edifício de energia zero (zero energy buildings) enquanto qualquer edifício cujo indicador de consumo for superior a $\mathrm{IC}_{\operatorname{maxD}}$ será considerado nível E, não cabendo ao RTQ-C estipular o limite máximo existente, ou possível, de um indicador de consumo.

Neste ponto, pode-se responder a mais um item identificado por Pérez-Lombard et al. (2009) no desenvolvimento de normas e regulamentos de eficiência energética de edifícios: como estabelecer os limites para os níveis de eficiência. Para o RTQ-C, o limite do nível máximo D foi baseado na prática construtiva brasileira e, a partir deste e de um edifício considerado eficiente, os demais limites foram determinados proporcionalmente ao intervalo obtido.

\section{Método prescritivo: sistema de iluminação artificial}

Os critérios do sistema de iluminação foram baseados na Norma 90.1 da ASHRAE (2007), porém com adaptações para a realidade brasileira. A ASHRAE apresenta limites de densidade de potência de iluminação interna para o edifício completo e para os ambientes separadamente, de acordo com as atividades exercidas em ambos. Os limites usados na ASHRAE são definidos pelo Commercial Building Energy Consumption Survey, CBECS (CBECS, 2003), um levantamento periódico do uso da energia em edifícios comerciais dos EUA. Ele coleta dados de área, atividade, materiais construtivos, fontes energéticas e uso para uma amostra de cerca de 5.000 edifícios por todo o território americano, o que representa estatisticamente os edifícios construídos no país. Desde 1992 O CBECS é a base de dados de edifícios não residenciais naquele país, com dados registrados desde 1986 (CBECS, 2003).

O Brasil teve seu primeiro levantamento nacional de uso da energia em edifícios comerciais iniciado em 2005 e publicado parcialmente em 2007 como uma pesquisa de mercado com o apoio do Procel (PROCEL, 2008a, 2008b). Na ausência de base de dados como a pesquisa de mercado ou o CBECS americano, os parâmetros para a definição dos níveis de eficiência do sistema de iluminação não podiam basear-se somente na densidade de potência de acordo com a atividade exercida no ambiente. Um estudo de custo do ciclo de vida da iluminação artificial somou-se aos limites de iluminância de acordo com sua atividade presentes na NBR 5413 - Iluminância de Interiores (ABNT, 1992), para a definição dos critérios-limite dos níveis de eficiência do sistema de iluminação. A densidade de potência de iluminação interna relativa à iluminância, com unidade em $\mathrm{W} / \mathrm{m}^{2} / 100$ lx, tornou-se o parâmetro para limitar os níveis de eficiência. Essa unidade uniformiza o nível para qualquer ambiente, independentemente de sua iluminância, permitindo também que se comparem as eficiências de cada sistema.

Assim, a Tabela 1 apresenta três diferentes ambientes com as características de seu sistema de iluminação. Tendo áreas, número de luminárias e potências por luminária distintos, esses parâmetros são normalizados na densidade de potência de iluminação. Sabe-se, através desse parâmetro, qual sistema consome menos (ambiente 2), mas não é possível identificar qual sistema é mais eficiente. Usando a iluminância, tem-se o "trabalho" exercido pelo sistema, obtido por parâmetros como o fluxo luminoso da lâmpada. Ao dividir o quanto o sistema consome para cada 100 lux que ele "produz", a densidade de potência de iluminação relativa permite que diferentes sistemas em diferentes ambientes apresentem eficiências comparáveis. Vê-se, portanto, que o ambiente 2, que consome menos $\left(9 \mathrm{~W} / \mathrm{m}^{2}\right)$, não é o mais eficiente, mas sim o menos eficiente, pois consome 2,25 W/m² para cada 100 lux de iluminância que proporciona. Já o ambiente 3 consome $2,22 \mathrm{~W} / \mathrm{m}^{2}$ para os mesmos 100 lux. 


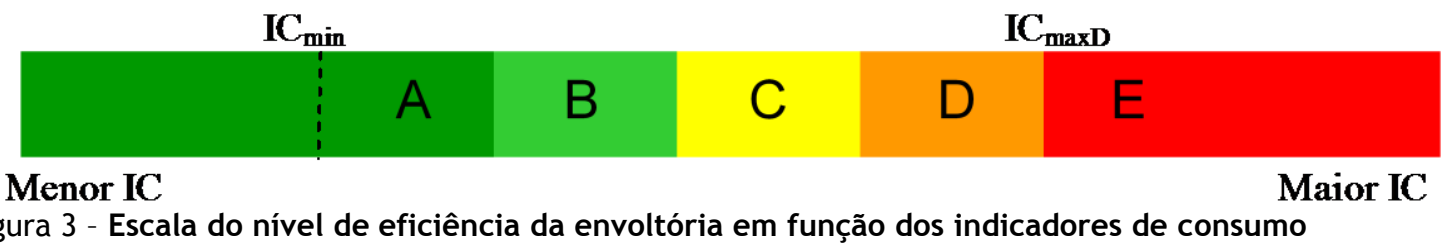

\begin{tabular}{c|c|c|c|c|c|c}
\hline Ambiente & Área $\left(\mathbf{m}^{2}\right)$ & $\begin{array}{c}\mathbf{P}(\mathbf{W}) \\
\text { luminária }\end{array}$ & $\begin{array}{c}\mathbf{N}^{\mathbf{0}} \\
\text { luminária }\end{array}$ & DPI $\left(\mathbf{W} / \mathbf{m}^{2}\right)$ & $\begin{array}{c}\text { Iluminância } \\
(\mathbf{l u x})\end{array}$ & $\begin{array}{c}\text { DPI relativa } \\
\left(\mathbf{W} / \mathbf{m}^{2} / \mathbf{1 0 0} \mathbf{~ l x}\right)\end{array}$ \\
\hline 1 & 50 & 70 & 8 & 11,2 & 500 & 2,24 \\
\hline 2 & 40 & 60 & 6 & 9,0 & 400 & 2,25 \\
\hline 3 & 60 & 60 & 10 & 10,0 & 450 & 2,22 \\
\hline
\end{tabular}

Tabela 1 - Características de três sistemas de iluminação

Dessa forma, usando a NBR 5413 (ABNT, 1992), foi possível desvincular a eficiência dos níveis de iluminância, o que foi necessário em função da ausência de pesquisas abrangentes no Brasil sobre as características dos edifícios aqui construídos e do uso da energia.

O nível de eficiência para o sistema de iluminação deve ser obtido mediante a comparação entre a densidade de potência de iluminação relativa limite $\left(\mathrm{DPI}_{\mathrm{RL}}\right)$, encontrada através do índice de ambiente (K), e a densidade de potência de iluminação final $\left(\mathrm{DPI}_{\mathrm{RF}}\right)$, obtida através do projeto luminotécnicoO procedimento descrito abaixo pretende alcançar o equivalente numérico de iluminação (EqNumDPI) que melhor descreva o sistema de iluminação do edifício após calculados sistemas em separado e após diversas ponderações:

(a) primeiramente, deve-se identificar todas as zonas de iluminação do ambiente e, em seguida, calcular um K para cada zona;

(b) deve-se encontrar uma DPI ${ }_{\mathrm{RL}}$ para cada zona de iluminação, de acordo com o índice de ambiente e com o nível de eficiência desejado. $\mathrm{O}$ regulamento apresenta uma tabela contendo algumas $\mathrm{DPI}_{\mathrm{RL}}$, outras devem ser encontradas por interpolação do K e da DPIRL;

(c) com o projeto luminotécnico, deve-se obter as $\mathrm{DPI}_{\mathrm{RF}}$;

(d) em seguida, deve-se garantir que cada $\mathrm{DPI}_{\mathrm{RF}}$ seja menor que a $\mathrm{DPI}_{\mathrm{RL}}$ para aquele nível de eficiência. Sendo menor, deve-se adotar o equivalente numérico daquele nível de eficiência para cada zona de iluminação; sendo maior, devese encontrar o nível de eficiência cuja $\mathrm{DPI}_{\mathrm{RF}}$ seja menor que a $\mathrm{DPI}_{\mathrm{RL}}$;

(e) encontrados todos os EqNumDPI para cada zona de iluminação, deve-se ponderá-los pela área das zonas, encontrando os EqNumDPI de cada ambiente; (f) aplicam-se os pré-requisitos para cada ambiente separadamente, o que pode gerar correções no EqNumDPI do ambiente caso este não atenda aos pré-requisitos de seu nível de eficiência. Dessa forma, obtêm-se os níveis de eficiência e os equivalentes numéricos de iluminação para cada ambiente; e

(g) o passo final é ponderar esses EqNumDPI pela área dos ambientes para se determinarem o equivalente numérico final do sistema de iluminação do edifício e, por conseguinte, seu nível de eficiência.

Além de determinar o nível de eficiência do sistema de iluminação individualmente, o cálculo identifica o EqNumDPI que deve participar da equação geral (Equação 1 neste artigo e Equação 2.1 no Regulamento), para se determinar o nível de eficiência do edifício completo. A ponderação pela área gera números fracionários, que devem ser usados até o final dos cálculos, incluindo seu uso na equação geral para a determinação da eficiência do edifício (Equação 1 neste artigo e Equação 2.1 no Regulamento).

\section{Método prescritivo: sistema de condicionamento de ar}

O sistema de condicionamento de ar é o mais simples de se determinar o nível de eficiência energética, desde que sejam usados equipamentos etiquetados pelo Inmetro como aparelhos de janela e splits high wall. Como já são etiquetados, basta verificar o nível de eficiência de cada aparelho e relacioná-lo ao equivalente numérico do arcondicionado, EqNumAC. Ambientes que possuem condicionadores com diferentes níveis de eficiência devem ter os EqNumAC dos condicionadores ponderados pela capacidade dos aparelhos. Em seguida, deve-se ponderar os EqNumAC de cada ambiente por sua área para encontrar o nível de eficiência final do sistema de condicionamento de ar. Este será o nível de 
eficiência presente na ENCE parcial do sistema de condicionamento de ar, e EqNum será usado na equação geral para a determinação da eficiência do edifício (Equação 1 neste artigo e Equação 2.1 no Regulamento).

A avaliação já é distinta para sistemas de condicionamento central. Inicialmente, todo edifício com carga térmica superior a $350 \mathrm{~kW}(99$ TR) deve conter um sistema central, exceto se comprovado o uso mais eficiente do sistema de condicionamento por splits ou aparelhos de janela. A comprovação se faz por análise de simultaneidade e abrange casos como edifícios empresariais com unidades consumidoras independentes, onde cada escritório poderá funcionar em horários distintos, sem controle no uso geral do sistema de condicionamento de ar.

Para sistemas centrais, há limites de COP (coefficent of performance, ou coeficiente de desempenho) ou IPLV (integrated part-load value) para condicionadores, resfriadores de líquido e torres de resfriamento, de acordo com a capacidade do equipamento e do nível de eficiência que se pode (ou se pretende) alcançar. Esses limites são baseados na Norma 90.1 da ASHRAE nas versões para nível D (1989), para nível C (1999) e para níveis B e A (2004). O que diferencia os níveis B e A são exigências de projetos específicas para se atingir o nível A. Essas exigências abrangem a automação, isolamento de zonas térmicas, uso do ciclo economizador, existência de faixa de temperatura de controle (deadband), recuperadores de calor, entre outras.

Obviamente, o método de simulação desvincula tais exigências do sistema de condicionamento de ar. Caso sejam comprovadas por simulação, podese adotar outras soluções de projeto do sistema central de condicionamento de ar que sejam eficientes e, portanto, que garantam um uso racional da eletricidade no edifício.

\section{Metodologia - parte 2: aplicação do RTQ-C \\ Edifício para o caso-base}

Santana (2006) levantou o uso da energia e características construtivas de cerca de 30 edifícios empresariais de escritórios. O edifício selecionado foi originado dessa pesquisa e apresenta as características mostradas no Quadro 1.

Edifícios de escritórios que contêm múltiplas unidades autônomas de consumo apresentam uma variabilidade extensa de sistemas de iluminação ou tipos de condicionamento de ar. Santana (2006) apresentou os resultados finais para os grupos analisados, mas não apresentou uma característica em comum para esse edifício. Dessa forma, tais dados foram estimados considerando-se o ano de construção do edifício. Estabeleceram-se um sistema de iluminação composto de lâmpadas T8 (32 W) e o condicionamento de ar com aparelhos tipo split hiwall, cuja eficiência é expressa pelo CEE (coeficiente de eficiência energética) de 2,7 W/W.

\section{Alternativas}

Foram realizadas modificações na envoltória, a fim de analisar o nível de eficiência segundo as alternativas:

(a) aumento das dimensões do edifício;

(b) rotação de $90^{\circ}$ no edifício;

(c) aumento na área de janela;

(d) aumento na área de janela com redução do fator solar dos vidros;

(e) aumento na área de janela com inserção de proteções solares;

(f) sistema de iluminação mais eficiente;

(g) sistema de condicionamento mais eficiente; e

(h) sistema de condicionamento em $76 \%$ dos ambientes de permanência prolongada.

Cabe salientar que o método prescritivo só inclui a opção de aproveitamento da luz natural por meio da simulação, assim esse aspecto não foi analisado pelo método prescritivo. Também não foram analisados os pré-requisitos dos sistemas, pois estes se caracterizam pelo atendimento obrigatório, não sendo passíveis de compensações como nas equações da envoltória. As Tabelas 2 e 3 apresentam as características para o caso-base, que é o edifício existente, e suas alternativas.

Cabe salientar algumas questões acerca dos dados apresentados nas Tabelas 2 e 3: 


\begin{tabular}{|l|l|}
\hline Atividade comercial & Múltiplos escritórios \\
\hline Localização & Florianópolis, SC \\
\hline Comprimento & 40 \\
\hline Largura & 17,5 \\
\hline Pé-direito & 2,8 \\
\hline Pavimentos & 10 \\
\hline Escritórios & $10 /$ pavimento \\
\hline Circulação & $1 /$ pavimento \\
\hline Ano & Década de 90 \\
\hline Vidros & Fumê \\
\hline PAF Norte & $16 \%$ \\
\hline PAF Leste & $35 \%$ \\
\hline PAF Sul & $16 \%$ \\
\hline PAF Oeste & $35 \%$ \\
\hline Área esc. tipo 1 & $78,75 \mathrm{~m}^{2}$ \\
\hline Área esc. tipo 2 & $56,83 \mathrm{~m}^{2}$ \\
\hline
\end{tabular}

Quadro 1 - Características gerais do edifício selecionado por Santana (2006)

\begin{tabular}{|c|c|c|c|c|c|c|c|}
\hline Parâmetro & Base & Alt1a & Alt1b & Alt2 & Alt3 & Alt4 & Alt5 \\
\hline Dimensões (m) & $17,5 \times 40$ & $40 \times 40$ & $40 \times 40$ & $17,5 \times 40$ & $17,5 \times 40$ & $17,5 \times 40$ & $17,5 \times 40$ \\
\hline Número pav. & 10 & 10 & 10 & 10 & 10 & 10 & 10 \\
\hline Pé-direito (m) & 2,8 & 2,8 & 2,8 & 2,8 & 2,8 & 2,8 & 2,8 \\
\hline $\begin{array}{l}\text { Orientação maiores } \\
\text { fachadas }\end{array}$ & $\begin{array}{l}\text { leste- } \\
\text { oeste }\end{array}$ & $\begin{array}{l}\text { leste- } \\
\text { oeste }\end{array}$ & $\begin{array}{l}\text { leste- } \\
\text { oeste }\end{array}$ & $\begin{array}{l}\text { norte- } \\
\text { sul }\end{array}$ & $\begin{array}{l}\text { leste- } \\
\text { oeste }\end{array}$ & $\begin{array}{l}\text { leste- } \\
\text { oeste }\end{array}$ & $\begin{array}{l}\text { leste- } \\
\text { oeste }\end{array}$ \\
\hline $\mathrm{PAF}_{\mathrm{t}}$ & $29 \%$ & $29 \%$ & $29 \%$ & $29 \%$ & $60 \%$ & $29 \%$ & $29 \%$ \\
\hline $\mathrm{PAF}_{\mathrm{O}}$ & $35 \%$ & $35 \%$ & $35 \%$ & $16 \%$ & $72 \%$ & $35 \%$ & $35 \%$ \\
\hline FS vidro & 0,87 & 0,87 & 0,87 & 0,87 & 0,87 & $\mathbf{0 , 2 0}$ & 0,87 \\
\hline $\begin{array}{l}\text { Proteção solar: } \\
\text { AVS e AHS (graus) }\end{array}$ & - & - & - & - & - & - & 35 e 30 \\
\hline $\mathrm{U}_{\mathrm{par}}\left(\mathrm{W} / \mathrm{m}^{2} \mathrm{~K}\right)$ & 2,01 & 2,01 & 2,01 & 2,01 & 2,01 & 2,01 & 2,01 \\
\hline $\mathrm{U}_{\mathrm{cob}}\left(\mathrm{W} / \mathrm{m}^{2} \mathrm{~K}\right)$ & 0,51 & 0,51 & 0,51 & 0,51 & 0,51 & 0,51 & 0,51 \\
\hline$\alpha_{\mathrm{par}}$ & 0,6 & 0,6 & 0,6 & 0,6 & 0,60 & 0,6 & 0,6 \\
\hline$\alpha_{\mathrm{cob}}$ & 0,7 & 0,7 & 0,7 & 0,7 & 0,7 & 0,7 & 0,7 \\
\hline $\begin{array}{l}\text { Iluminação média } \\
\text { escrit. }\left(\mathrm{W} / \mathrm{m}^{2}\right)\end{array}$ & 12,36 & 12,36 & 12,01 & 12,36 & 12,36 & 12,36 & 12,36 \\
\hline $\begin{array}{l}\text { Iluminação média } \\
\left(\mathrm{W} / \mathrm{m}^{2}\right)\end{array}$ & 12,53 & 12,53 & 12,21 & 12,53 & 12,53 & 12,53 & 12,53 \\
\hline $\begin{array}{l}\text { Ambientes } \\
\text { condicionados }\end{array}$ & $100 \%$ & $100 \%$ & $100 \%$ & $100 \%$ & $100 \%$ & $100 \%$ & $100 \%$ \\
\hline $\begin{array}{l}\text { Tipo de condicio- } \\
\text { namento de ar }\end{array}$ & split & split & split & split & split & split & split \\
\hline CEE (W/W) & 2,7 & 2,7 & 2,7 & 2,7 & 2,7 & 2,7 & 2,7 \\
\hline
\end{tabular}

Nota: Em negrito, a medida modificada.

Tabela 2 - Características do caso-base e alternativas analisadas, de 1 a 3 


\begin{tabular}{|c|c|c|c|c|c|c|c|}
\hline Parâmetro & Alt6 & Alt7 & Alt8 & Alt9 & Alt10 & Alt11 & Alt12 \\
\hline Dimensões (m) & $17,5 \times 40$ & $17,5 \times 40$ & $17,5 \times 40$ & $17,5 \times 40$ & $17,5 \times 40$ & $17,5 \times 40$ & $17,5 \times 40$ \\
\hline Número pav. & 10 & 10 & 10 & 10 & 10 & 10 & 10 \\
\hline Pé-direito (m) & 2,8 & 2,8 & 2,8 & 2,8 & 2,8 & 2,8 & 2,8 \\
\hline $\begin{array}{l}\text { Orientação maiores } \\
\text { fachadas }\end{array}$ & $\begin{array}{l}\text { leste- } \\
\text { oeste }\end{array}$ & $\begin{array}{l}\text { leste- } \\
\text { oeste }\end{array}$ & $\begin{array}{l}\text { leste- } \\
\text { oeste }\end{array}$ & $\begin{array}{l}\text { leste- } \\
\text { oeste }\end{array}$ & $\begin{array}{l}\text { leste- } \\
\text { oeste }\end{array}$ & $\begin{array}{l}\text { leste- } \\
\text { oeste }\end{array}$ & a definir \\
\hline $\mathrm{PAF}_{\mathrm{t}}$ & $60 \%$ & $60 \%$ & $60 \%$ & $29 \%$ & $29 \%$ & $29 \%$ & a definir \\
\hline $\mathrm{PAF}_{\mathrm{O}}$ & $72 \%$ & $72 \%$ & $72 \%$ & $35 \%$ & $35 \%$ & $35 \%$ & a definir \\
\hline FS vidro & 0,20 & 0,87 & 0,87 & 0,87 & 0,87 & 0,87 & a definir \\
\hline $\begin{array}{l}\text { Proteção solar: } \\
\text { AVS e AHS } \\
\text { (graus) }\end{array}$ & - & 35 e 0 & 35 e 30 & & - & - & a definir \\
\hline $\mathrm{U}_{\mathrm{par}}\left(\mathrm{W} / \mathrm{m}^{2} \mathrm{~K}\right)$ & 2,01 & 2,01 & 2,01 & 2,01 & 2,01 & 2,01 & 2,01 \\
\hline $\mathrm{U}_{\mathrm{cob}}\left(\mathrm{W} / \mathrm{m}^{2} \mathrm{~K}\right)$ & 0,51 & 0,51 & 0,51 & 0,51 & 0,51 & 0,51 & 0,51 \\
\hline$\alpha_{\mathrm{par}}$ & 0,6 & 0,6 & 0,6 & 0,6 & 0,6 & 0,6 & 0,6 \\
\hline$\alpha_{\mathrm{cob}}$ & 0,7 & 0,7 & 0,7 & 0,7 & 0,7 & 0,7 & 0,7 \\
\hline $\begin{array}{l}\text { Iluminação média } \\
\text { escrit. }\left(\mathrm{W} / \mathrm{m}^{2}\right)\end{array}$ & 12,36 & 12,36 & 12,36 & 11,23 & 12,36 & 12,36 & a definir \\
\hline $\begin{array}{l}\text { Iluminação média } \\
\left(\mathrm{W} / \mathrm{m}^{2}\right)\end{array}$ & 12,53 & 12,53 & 12,53 & 11,50 & 12,53 & 12,53 & a definir \\
\hline $\begin{array}{l}\text { Ambientes } \\
\text { condicionados }\end{array}$ & $100 \%$ & $100 \%$ & $100 \%$ & $100 \%$ & $100 \%$ & $24 \%$ & $100 \%$ \\
\hline $\begin{array}{l}\text { Tipo de } \\
\text { condicionamento } \\
\text { de ar }\end{array}$ & split & split & split & split & split & split & split \\
\hline CEE (W/W) & 2,7 & 2,7 & 2,7 & 2,7 & 3,02 & 3,02 & a definir \\
\hline
\end{tabular}

Tabela 3 - Características das alternativas 4 a 9

(a) a alteração das dimensões do edifício refletese na iluminação dos ambientes internos, pois, ao alterar a forma, alteram-se o tamanho dos ambientes e, portanto, o projeto luminotécnico. Para fins de comparação, essas mudanças não foram consideradas na alternativa Alt1a, enquanto a alternativa Alt1b apresenta as consequências totais da mudança nas dimensões do edifício. Já as características da envoltória são idênticas entre essas alternativas, pois o $\mathrm{PAF}_{\mathrm{t}} \mathrm{e}$ ângulos de sombreamento (AVS e AHS) são proporcionais ao caso-base;

(b) o aumento na área de abertura envidraçada foi proporcional às áreas de cada fachada do casobase. Assim, $\mathrm{PAF}_{\mathrm{t}}$ de $60 \%$ refere-se a percentuais de $33 \%$ e $72 \%$ de abertura envidraçada nas fachadas;

(c) as proteções solares foram projetadas atendendo às condições de insolação, de acordo com a orientação solar de cada fachada. Os ângulos apresentados na alternativa 5 da Tabela $2 \mathrm{e}$ nas alternativas 7 e 8 da Tabela 3 são o resultados da média ponderada dos ângulos de cada proteção pela área de abertura envidraçada (janela) atendida pela proteção solar; (d) o sistema de iluminação refere-se à iluminação média dos ambientes de escritório e em conjunto com a circulação, cuja densidade de potência permaneceu constante em $14,2 \mathrm{~W} / \mathrm{m}^{2}$ para qualquer caso. Nos escritórios, o caso-base obteve densidades de $12 \mathrm{~W} / \mathrm{m}^{2}$ e $13 \mathrm{~W} / \mathrm{m}^{2}$, usando lâmpadas T8 com luminárias com aletas para evitar o ofuscamento;

(e) o percentual de ambientes condicionados refere-se à área de ambientes de permanência prolongada com condicionamento de ar em relação ao total da área de ambientes de permanência prolongada, ou seja, aos escritórios. Na Tabela 3, $24 \%$ dos ambientes não condicionados configuram-se como dois ambientes, por pavimento, sem condicionamento artificial; 3

(f) a alternativa 12 não apresenta parâmetros, pois será formada das medidas que resultaram em um mais alto nível de eficiência energética composto das etiquetas parciais. Embora o objetivo deste artigo não seja alcançar elevados níveis de eficiência, é interessante apresentar um caso final de resultados positivos.

Por fim, o método apresentado que pode indicar os melhores parâmetros para a alternativa 12 
possibilita a aplicação da penúltima questão levantada por Pérez-Lombard et al. (2009) sobre que melhoramentos recomendar. A própria avaliação de diferentes medidas de conservação de energia indicará onde realizar e quais as melhores intervenções no edifício, respeitadas as limitações do método, que também são discutidas ao longo deste artigo.

\section{Determinação dos níveis de eficiência}

Os níveis de eficiência da envoltória foram obtidos a partir da Equação 2 apresentada neste artigo, aplicável a edifícios da zona bioclimática 3 Florianópolis - com área de projeção superior a $500 \mathrm{~m}^{2}$. Os níveis de eficiência de interesse são os obtidos com o indicador de consumo e foram utilizados na etapa final, considerando que os prérequisitos são atendidos. Para fins de comparação, também se avaliaram os níveis de eficiência considerando-se as transmitâncias térmicas e absortância solar do edifício real somente para a etiqueta parcial da envoltória.

Para o sistema de iluminação, encontrou-se o índice de ambiente para cada escritório e para a circulação sem a necessidade de dividir os ambientes em zonas de iluminação. Adotou-se uma iluminância média de 500 lux, a partir da qual foram realizados os cálculos do projeto luminotécnico.

Já o sistema de condicionamento de ar teve avaliação simplificada, pois o nível de eficiência de cada aparelho foi obtido comparando-se o CEE do aparelho com os limites tabelados pelo Inmetro. Considerou-se que todas as unidades condensadoras são sombreadas e, portanto, os prérequisitos são atendidos.

Para finalizar, considerou-se que os pré-requisitos gerais foram atendidos e que não há bonificações a contabilizar. Os equivalentes numéricos foram inseridos na Equação 1 com as respectivas áreas calculadas. No edifício em análise, essas são: área útil $(\mathrm{AU})$, área condicionada $(\mathrm{AC})$ e área de ambientes de permanência transitória (APT). Os $24 \%$ de área de ambientes não condicionados da alternativa 8 não podem ser contabilizados como ANC, visto não terem comprovação de condições de conforto térmico pela simulação. Assim, não há ambientes não condicionados simulados para a avaliação da ventilação natural, sendo $\mathrm{ANC}=0$.

\section{Resultados}

\section{ENCE parcial da envoltória}

A Figura 4 apresenta a escala do indicador de consumo para o caso-base, que é válida para as envoltórias das demais alternativas, exceto para as alternativas 1a e 1b. O indicador de consumo de envoltória do caso-base foi de 97, nível de eficiência E. Os pré-requisitos estão de acordo com o nível encontrado pelo indicador de consumo. Deve-se salientar que foi inserido o $\mathrm{PAF}_{\mathrm{O}}$ de $35 \%$ na Equação 2, visto que este é maior que o PAF + $20 \% \mathrm{PAF}_{\mathrm{t}}(34,8 \%)$. A Tabela 4 apresenta os indicadores de consumo para as demais alternativas, cujo IC foi calculado com o $\mathrm{PAF}_{\mathrm{t}}$ de $29 \%$ somente na alternativa 2 , onde a orientação solar é alterada.

A Figura 5 apresenta a escala do indicador de consumo das alternativas 1a e 1b, que apresentam envoltórias idênticas. $\mathrm{O}$ fator de forma obtido para as dimensões de $40 \mathrm{~m}$ x $40 \mathrm{~m}$ e 10 pavimentos foi de 0,14. Esse valor é menor que o FF mínimo da Equação 2 e, portanto, foi utilizado o FF limite de 0,15 . O $\mathrm{IC}_{\text {env }}$ foi de 43,16, indicando ser uma envoltória de nível de eficiência C. Esse resultado mostra-se condizente com o caso-base, visto ambos apresentarem a mesma envoltória na mesma zona bioclimática.

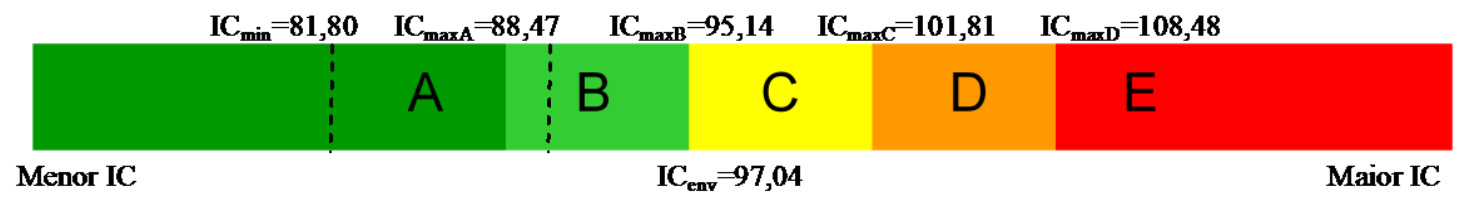

Figura 4 - Escala do indicador de consumo para a envoltória do caso-base

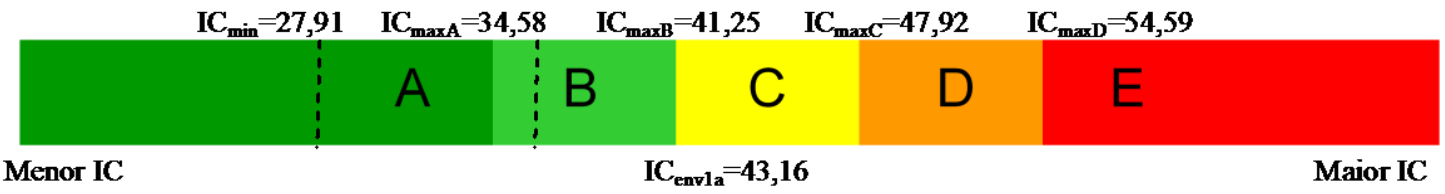

Figura 5 - Escala do indicador de consumo para a envoltória das alternativas 1a e 1b 
A Tabela 4 apresenta o indicador de consumo, o nível de eficiência obtido para os pré-requisitos de transmitância térmica e absortância solar de paredes e coberturas ${ }^{3}$. Pela tabela, qualquer um dos pré-requisitos não cumpridos reduz a eficiência para o nível em que o pré-requisito é atendido. Como não foram alteradas as características dos pré-requisitos, os níveis de eficiência tendem a ser, no melhor caso, $\mathrm{C}$ para qualquer alternativa. Portanto, a análise será realizada sem considerar os pré-requisitos.

Pela Tabela 4, vê-se que a modificação das dimensões em nada alterou o nível de eficiência das alternativas 1a e $1 \mathrm{~b}$, embora tenha alterado o indicador de consumo, o que foi mostrado com mais detalhes na Figura 3.

Já as demais alternativas podem ser comparadas entre si, tanto pelo indicador de consumo quanto pelo nível de eficiência. Nestes, vê-se que a mudança da orientação solar do edifício alterou a eficiência da alternativa 2 para nível $B$. Ao contrário das demais, esta usou o $\mathrm{PAF}_{\mathrm{t}}$ na equação, enquanto as outras usaram o $\mathrm{PAF}_{\mathrm{O}}$. A redução do fator solar dos vidros também beneficiou a alternativa 4 , passando de nível $\mathrm{C}$ para $\mathrm{B}$, assim como ocorrido com a alternativa 7 , que combinou o aumento do $\mathrm{PAF}_{\mathrm{t}}$ (mas foi aplicado o $\mathrm{PAF}_{\mathrm{O}}$, como já comentado) e sombreamento da proteção solar (AVS e AHS). No entanto, o aumento do $\mathrm{PAF}_{\mathrm{t}}$ isoladamente prejudicou a eficiência, que chegou a nível E na alternativa 3, e a redução do fator solar não compensou esse prejuízo, como visto na alternativa 6 . Por fim, o aumento da área envidraçada e a tentativa de compensar a eficiência com o excessivo sombreamento não são bemvindos pelo método, pois a alternativa 8 apresentou nível $\mathrm{C}$ ao inserir maior sombreamento que o necessário.

Por fim, vale ressaltar que as medidas propostas não geram bons resultados caso os pré-requisitos não sejam atendidos. Pela Tabela 4, a eficiência final não passa de nível $\mathrm{C}$ devido às cores adotadas nas fachadas e na cobertura.

\section{ENCE parcial do sistema de iluminação}

A análise é válida para o caso-base, alternativa $1 \mathrm{~b}$ e alternativa 9. A Tabela 5 apresenta os resultados da etiqueta parcial do sistema de iluminação para esses três casos, níveis $\mathrm{D}$ para o caso-base, e alternativa $1 \mathrm{~b}$ e nível B para a alternativa 9, considerando atendimento aos pré-requisitos de iluminação. Assim, não há exigência para nível D, e os ambientes de nível B devem apresentar controles manuais que visualizem todo o ambiente e deve haver controles individuais para as fileiras de luminárias próximas às janelas. Por ser resultados de uma ponderação pela área do ambiente, o equivalente numérico do sistema de iluminação raramente é um número inteiro.

\section{ENCE parcial do sistema de condicionamento de ar}

A alternativa 10 refere-se ao sistema de condicionamento de ar. A partir da alteração de $100 \%$ dos aparelhos split de eficiência de 2,70 W/W para 3,02 W/W, passou-se do nível de eficiência D para o nível A. As demais análises do condicionamento de ar são realizadas a seguir.

\section{ENCE final do edifício}

A Equação 1 foi aplicada para ponderação dos equivalentes numéricos finais. As variáveis utilizadas são apresentadas na Tabela 6. Em todos os casos, considerou-se que os pré-requisitos da envoltória foram atendidos. A alternativa 12 foi elaborada utilizando-se os resultados da envoltória da alternativa 5, de iluminação da alternativa 9 e de condicionamento de ar da alternativa 10.

Os resultados variaram de nível $\mathrm{A}$, na alternativa 12, a nível E, na alternativa 6. A combinação das etiquetas parciais da envoltória, iluminação e condicionamento de ar demonstra a relação de pesos da Equação 1. Nesta, vê-se que o elevado nível de eficiência da envoltória na alternativa 5 ou do sistema de condicionamento de ar na alternativa 11 não é mantido na eficiência final, visto que os demais sistemas apresentam baixas eficiências.

Ainda, a relação da equação geral de avaliação do nível de eficiência do RTQ-C é ajustada pela relação de áreas que cada nível representa. As alternativas 10 e 11 apresentam equivalentes numéricos idênticos. No entanto, a alternativa 11 alcança apenas nível $\mathrm{C}$, devido à eliminação de $24 \%$ da parcela de sua área no montante da área condicionada. O nível de eficiência pode ainda baixar mais caso o percentual de área não condicionada seja maior, chegando a nível E caso $100 \%$ do edifício não seja condicionado e não tenha sido compensado com a simulação da ventilação natural.

\footnotetext{
${ }^{3}$ O edifício não possui dispositivo de iluminação zenital, portanto este item não foi avaliado.
} 


\begin{tabular}{|c|c|c|c|c|c|c|c|}
\hline \multirow{2}{*}{$\begin{array}{c}\text { Caso-base ou } \\
\text { alternativa }\end{array}$} & \multirow{2}{*}{$\begin{array}{l}\text { Principal } \\
\text { medida }\end{array}$} & \multicolumn{2}{|c|}{ IC } & \multicolumn{3}{|c|}{ Pré-requisitos } & \multirow{2}{*}{$\begin{array}{c}\text { Eficiência } \\
\text { final }\end{array}$} \\
\hline & & IC & Eficiência & $\mathbf{U}_{\text {cob }}$ & $\mathbf{U}_{\mathrm{par}}$ & $\boldsymbol{\alpha}_{\mathrm{par}} \mathbf{e} \boldsymbol{\alpha}_{\mathrm{cob}}$ & \\
\hline Base & - & 97,04 & $\mathrm{C}$ & $\mathrm{C}$ & $\mathrm{C}$ & $\mathrm{C}$ & $\mathrm{C}$ \\
\hline Alt1a & Dimensões & 43,16 & $\mathrm{C}$ & $\mathrm{C}$ & $\mathrm{C}$ & $\mathrm{C}$ & $\mathrm{C}$ \\
\hline Alt1b & Dimensões & 43,16 & $\mathrm{C}$ & $\mathrm{C}$ & $\mathrm{C}$ & $\mathrm{C}$ & $\mathrm{C}$ \\
\hline Alt2 & Orientação & 93,99 & B & B & B & $\mathrm{C}$ & $\mathrm{C}$ \\
\hline Alt3 & $\mathrm{PAF}_{\mathrm{t}}$ & 115,35 & $\mathrm{E}$ & $\mathrm{E}$ & $\mathrm{E}$ & $\mathrm{E}$ & $\mathrm{E}$ \\
\hline Alt4 & Fator solar & 93,79 & B & B & B & $\mathrm{C}$ & $\mathrm{C}$ \\
\hline Alt5 & $\mathrm{AVS}+\mathrm{AHS}$ & 77,70 & A & A & A & $\mathrm{C}$ & $\mathrm{C}$ \\
\hline Alt6 & $\mathrm{PAF}_{\mathrm{t}}+\mathrm{FS}$ & 112,59 & $\mathrm{E}$ & $\mathrm{E}$ & $\mathrm{E}$ & $\mathrm{E}$ & $\mathrm{E}$ \\
\hline Alt7 & $\mathrm{PAF}_{\mathrm{t}}+\mathrm{AVS}$ & 88,91 & B & B & $\mathrm{B}$ & $\mathrm{C}$ & $\mathrm{C}$ \\
\hline Alt8 & $\begin{array}{c}\mathrm{PAF}_{\mathrm{t}}+\mathrm{AVS}+ \\
\text { AHS }\end{array}$ & 96,71 & $\mathrm{C}$ & $\mathrm{C}$ & $\mathrm{C}$ & $\mathrm{C}$ & $\mathrm{C}$ \\
\hline
\end{tabular}

Tabela 4 - Níveis de eficiência da envoltória obtidos para o caso-base e para as demais alternativas

\begin{tabular}{|c|c|c|c|c|c|c|}
\hline \multirow{2}{*}{$\begin{array}{l}\text { Caso-base ou } \\
\text { alternativa }\end{array}$} & \multirow{2}{*}{ Principal medida } & \multicolumn{4}{|c|}{ Eq Numérico } & \multirow{2}{*}{$\begin{array}{c}\text { Eficiência } \\
\text { final }\end{array}$} \\
\hline & & Esc tipo 1 & Esc tipo 2 & Circulação & Total & \\
\hline Base & - & 2 & 2 & 1 & 1,97 & $\mathrm{D}$ \\
\hline Alt1b & - & 2 & 2 & 1 & 1,97 & $\mathrm{D}$ \\
\hline Alt9 & $\begin{array}{l}\text { Conjunto: luminária } \\
\text { /lâmpada/ reator }\end{array}$ & 4 & 4 & 1 & 3,90 & B \\
\hline
\end{tabular}

Tabela 5 - Níveis de eficiência do sistema de iluminação obtidos para o caso-base e para a alternativa 9

\begin{tabular}{l|c|c|c|c|c|c|c|c|c}
\hline & \multicolumn{4}{|c|}{ Áreas } & \multicolumn{3}{c|}{ Equivalentes numéricos } & PT & \multirow{2}{*}{ Eficiência } \\
\cline { 2 - 10 } & AU & AC & ANC & APT & Envoltória & Iluminação & Cond. de ar & Edif. & \\
\hline Caso-base & 6.800 & 6.184 & 0 & 616 & 3 & 1,97 & 2 & 2,45 & D \\
\hline Alt1a & 6.800 & 6.184 & 0 & 616 & 3 & 1,97 & 2 & 2,45 & D \\
\hline Alt1b & 6.800 & 6.184 & 0 & 616 & 3 & 1,97 & 2 & 2,45 & D \\
\hline Alt2 & 6.800 & 6.184 & 0 & 616 & 4 & 1,97 & 2 & 2,73 & C \\
\hline Alt3 & 6.800 & 6.184 & 0 & 616 & 1 & 1,97 & 2 & 1,91 & D \\
\hline Alt4 & 6.800 & 6.184 & 0 & 616 & 4 & 1,97 & 2 & 2,73 & C \\
\hline Alt5 & 6.800 & 6.184 & 0 & 616 & 5 & 1,97 & 2 & 3,00 & C \\
\hline Alt6 & 6.800 & 6.184 & 0 & 616 & 1 & 1,97 & 2 & 1,91 & E \\
\hline Alt7 & 6.800 & 6.184 & 0 & 616 & 4 & 1,97 & 2 & 2,73 & C \\
\hline Alt8 & 6.800 & 6.184 & 0 & 616 & 3 & 1,97 & 2 & 2,45 & D \\
\hline Alt9 & 6.800 & 6.184 & 0 & 616 & 3 & 3,90 & 2 & 3,03 & C \\
\hline Alt10 & 6.800 & 6.184 & 0 & 616 & 3 & 1,97 & 5 & 3,55 & B \\
\hline Alt11 & 6.800 & 4.700 & 0 & 616 & 3 & 1,97 & 5 & 2,91 & C \\
\hline Alt12 & 6.800 & 6.184 & 0 & 616 & 5 & 3,90 & 5 & 4,67 & A \\
\hline
\end{tabular}

Tabela 6 - Níveis de eficiência finais das alternativas analisadas 


\section{Discussão: requisitos da envoltória}

A análise acima ainda exige comentários acerca das variáveis envolvidas na Equação 2. A seguir, são discutidas algumas questões envolvendo as equações em si, a forma do edifício e as aberturas que compõem a envoltória.

\section{Limites impostos ao fator de forma}

As equações são derivadas de regressão linear multivariada. Sendo assim, baseiam-se em um universo amostrado. Como uma regressão matemática, ela permite que qualquer número seja inserido; como uma equação estatística que descreve uma realidade, ela possui limitações.

As equações foram obtidas a partir da simulação do desempenho termoenergético no programa EnergyPlus (CRAWLEY, 2001) de protótipos de edifícios definidos através de um levantamento. Esse levantamento baseou-se em amostras fotográficas colhidas em cinco capitais brasileiras. Obtiveram-se fotografias de 1.103 edificações comerciais, públicas e de serviços que, tratadas estatisticamente, geraram dados para as sete atividades comerciais. As características amostradas foram: dimensões, número de pavimentos, área de vidro, tipo de vidro e existência e dimensão das proteções solares (CARLO; GHISI; LAMBERTS, 2003). Essas características permitiram gerar tipologias específicas que subsidiaram a escolha de um edifício real para coletar dados das características de uso, como cargas internas de iluminação e tipo de condicionamento de ar. Ao final, foram obtidas dez tipologias de edifícios (algumas divididas em subcategorias) representativos da realidade construtiva brasileira. Esses edifícios, juntamente com alternativas contendo alterações em suas características de acordo com os resultados do levantamento, foram então modelados e simulados para gerar dados de consumo usados na elaboração das equações de regressão (CARLO; LAMBERTS, 2008).

Vê-se, portanto, que as equações são baseadas em modelos que representam o que mais se constrói no país. São generalistas e descrevem com mais exatidão o desempenho das volumetrias mais comuns existentes na paisagem urbana (Figura 6). Assim, a volumetria tornou-se um fator limitante no uso das equações. Edificações com volumes pouco comuns, ou muito pequenas ou muito grandes, não são apropriadamente descritas pelas equações, e deve-se, portanto, adotar os limites máximo ou mínimo do fator de forma, indicador da volumetria da edificação. Foi o que ocorreu nas alternativas 1a e $1 b$, onde o fator de forma chegou a 0,14 , sendo o limite mínimo a ser inserido na equação 0,15 . Esse aspecto, no entanto, não prejudica a avaliação da envoltória, visto que ela é comparativa a outros modelos de mesma volumetria.

Vale salientar ainda que o levantamento respondeu à primeira pergunta identificada por PérezLombard et al. (2009): o que deve ser avaliado. Para tanto, foi necessário conhecer as edificações existentes. Igualmente, a pergunta "A que o edifício deve ser comparado?" é também respondida: qualquer envoltória avaliada pelo método prescritivo é comparada a um caso dentre as 1.103 amostras obtidas no levantamento.

\section{Cálculo do fator de forma}

A regressão também justifica outros procedimentos de cálculo adotados no regulamento. A área da envoltória $\left(\mathrm{A}_{\mathrm{env}}\right)$ é composta de área de fachadas e área de cobertura e faz parte do cálculo do fator de forma $\left(\mathrm{A}_{\mathrm{env}} /\right.$ volume$)$. Como é um indicador da volumetria do edifício, deve-se considerar a área de cobertura do edifício mesmo se ela for inclinada e, como o regulamento refere-se a ambientes externos, beirais e marquises devem ser desconsiderados da área de cobertura que participa da área da envoltória. 


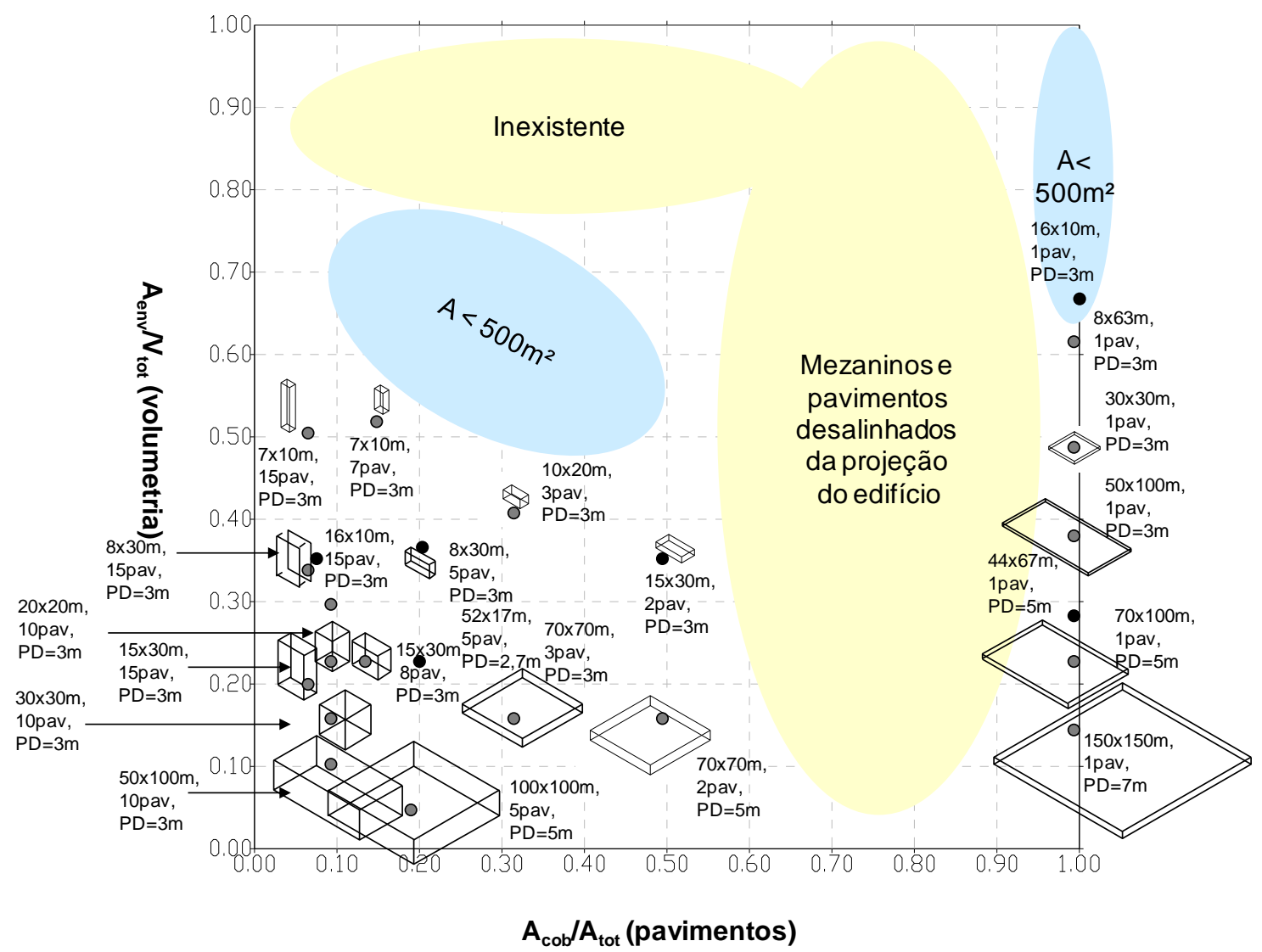

Nota: Os pontos em preto referem-se ao fator de forma e ao fator altura dos protótipos simulados, enquanto os pontos em cinza são outras volumetrias investigadas nas etapas iniciais da pesquisa, descrita em Carlo e Lamberts (2007).

Figura 6 - Fatores de forma investigados no desenvolvimento das equações

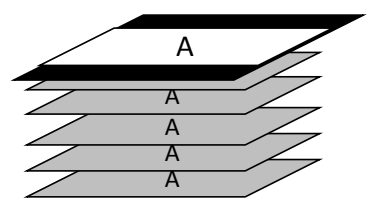

$\mathrm{FA}_{1}=\mathrm{A}_{\mathrm{cob}} / \mathrm{A}_{\text {tot }}=100 / 500=0,20$

$A=100 \mathrm{~m}^{2}$

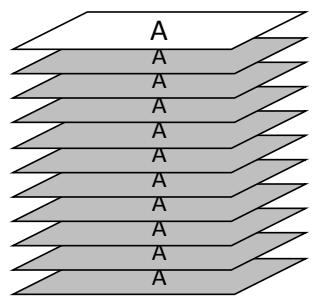

$\mathrm{FA}_{2}=\mathrm{A}_{\mathrm{cob}} / \mathrm{A}_{\mathrm{tot}}=100 / 1000=0,10$

$A=100 \mathrm{~m}^{2}$

Figura 7 - Desenho esquemático representando as áreas de piso e de projeção da cobertura de dois edifícios, um com 5 pavimentos e outro com 10 pavimentos

Devem ser consideradas como parte da envoltória todas as superfícies em contato com o ambiente externo que compõem o fechamento do edifício. Mas há exceções: edifícios com pilotis apresentam um piso em contato com o ambiente externo, assim como projeções de partes do edifício sobre os pavimentos inferiores. Estes não são computados no cálculo da envoltória, pois a relação de $\mathrm{A}_{\mathrm{env}}$ estabelecida para cálculo do fator de forma seria descaracterizada ao incluir uma área de superfície que não descrevesse a composição do volume.
Durante o desenvolvimento da equação, os pisos dos edifícios representativos não foram incluídos no cálculo da área da envoltória quando o FF foi inserido como variável independente da regressão. Dessa forma, a inclusão de uma área "extra" na área da envoltória resultaria numa descrição incorreta da volumetria do edifício e, portanto, no fator de forma inserido na equação. 


\section{Fator altura}

O fator altura é composto da razão entre a área de projeção da cobertura $\left(\mathrm{A}_{\mathrm{pcob}}\right)$ e a área total de piso do edifício $\left(\mathrm{A}_{\mathrm{tot}}\right)$. Indica o número de pavimentos e, junto com o fator de forma, descreve a geometria do edifício. Deve-se sempre considerar a área de piso do edifício excluindo os subsolos, exceto se estes forem parcialmente expostos (uma de suas fachadas estiver em contato com o ambiente exterior). Já a área de projeção da cobertura $^{4}$ deve também excluir os beirais e as marquises, conforme mostrado na Figura 7. Nessa figura, o fator altura do edifício 1 foi calculado excluindo-se as projeções da cobertura para além do alinhamento do edifício. Já o fator altura do edifício 2 foi calculado considerando-se a área total da cobertura.

A relação entre a área de projeção da cobertura e a área total também descreve os mezaninos. Um edifício hipotético de $100 \mathrm{~m}^{2}$ e 1 pavimento tem fator altura de 1 , pois tanto $A_{\text {pcob }}$ quanto $A_{\text {tot }}$ são $100 \mathrm{~m}^{2}$. Mas se ele possui pé-direito de $5 \mathrm{~m}$ contendo um mezanino de $50 \mathrm{~m}^{2}$, sua área total é de $150 \mathrm{~m}^{2} \mathrm{e}$, portanto, o fator altura passa a ser 0,75 (na Figura 6, é a área delimitada como "mezaninos e pavimentos desalinhados da projeção do edifício"). Com dois pavimentos, tendo assim $\mathrm{A}_{\text {tot }}$ de $200 \mathrm{~m}^{2}$, seu FA já seria 0,5. Vê-se a redução gradual do $\mathrm{FA}$ em função do aumento da área de piso sem alterar a projeção da cobertura. Esse fator, juntamente com o fator de forma, apresenta participação essencial na equação.

\section{Orientação do edifício e das proteções solares}

A orientação do edifício não é incluída no RTQ-C como parâmetro determinante da eficiência, embora seja participante. Sabe-se que é um parâmetro de grande influência no desempenho de um edifício, seja nas regiões de clima frio ou nas regiões de clima quente. Dois motivos levaram a não incluir a orientação do edifício como parâmetro determinante da eficiência:

(a) a impossibilidade de se optar pela orientação do edifício em função da forma e das dimensões do terreno, o que é muito comum nos centros urbanos. Pode-se afirmar que os edifícios deveriam ter sua eficiência classificada em função do terreno, pois a escolha do terreno é parte inicial de um projeto; $\mathrm{e}$

\footnotetext{
${ }^{4}$ Não confundir com área de cobertura para cálculo da envoltória, que também exclui beirais e marquises. Enquanto a primeira é a área completa medida na superfície, seja ela inclinada ou até curva, a segunda é uma área de projeção horizontal dessa cobertura.
}

(b) uma classificação que envolva o potencial de eficiência do terreno ou a eficiência do edifício em função da orientação é um avanço que pode ser integrado a versões futuras, não cabendo à primeira versão de um regulamento inédito no país. Essa é uma questão que terá tempo para discussão pela sociedade científica e mercadológica, a fim de se estabelecerem os critérios mais apropriados para a avaliação da eficiência em função da orientação, de acordo com as necessidades ante a realidade brasileira.

Assim como a orientação do edifício, as proteções solares não são diferenciadas por fachadas nas equações. No entanto, na determinação dos parâmetros que descrevem as proteções, AVS e AHS, deve-se calcular os ângulos apropriados para cada janela e orientação e, posteriormente, ponderá-los para um AVS e/ou AHS final do edifício completo para inserção na equação (PROCEL, 2009). Esse procedimento foi realizado nas alternativas 5, 7 e 8. A qualidade de projeto foi considerada na definição dessas alternativas como recomendado pelo regulamento, sendo ainda atribuição do arquiteto, que deve adotar máscaras e outros recursos no projeto das proteções. Brises e outros tipos de proteção mais complexos não têm participação complementar na avaliação pelo método prescritivo, mas podem ser avaliados pelo método da simulação.

Deve-se alertar que o método prescritivo considera a condição desfavorável da fachada oeste, avaliada em relação à área de aberturas envidraçadas. Caso o percentual de área de aberturas da fachada oeste $\left(\mathrm{PAF}_{\mathrm{O}}\right)$ seja maior que o percentual de área de aberturas do edifício $\left(\mathrm{PAF}_{\mathrm{t}}\right)$ mais $20 \%$ deste, devese adotar o $\mathrm{PAF}_{\mathrm{O}}$ na equação. Dessa forma, grandes aberturas envidraçadas na fachada oeste têm maior impacto na eficiência do edifício que as áreas envidraçadas das demais fachadas, reduzindo o indicador de consumo. Esse exemplo ocorreu na alternativa 2, a única em que $\mathrm{o} \mathrm{PAF}_{\mathrm{O}}$ não substituiu o $\mathrm{PAF}_{\mathrm{t}}$ na equação de obtenção do indicador de consumo (Equação 2). Esse fator foi determinante na obtenção do nível B da envoltória dessa alternativa.

\section{Aberturas envidraçadas}

A equação não descreve apropriadamente vidros de elevado desempenho. É uma limitação mostrada em seu desenvolvimento e se origina da ausência do fator solar como dado de entrada direto na simulação no programa EnergyPlus. Ele foi adotado na equação por ser o parâmetro que melhor descreve o desempenho do vidro, mas as características do vidro para modelagem no programa referem-se a refletâncias, absortâncias e 
emissividades. Assim, a conversão de fator solar para as outras propriedades térmicas dos vidros não foi suficiente com os dados obtidos por catálogos dos fabricantes devido a limitações, como tipo de dado e forma de cálculo pelos fabricantes. $^{5}$

A alternativa 4 elevou o nível de eficiência do caso-base de C para B. No entanto, edifícios com grandes áreas envidraçadas nas fachadas cujo elevado desempenho baseia-se na qualidade de seus vidros, o que dispensa a proteção solar, como informado por seus fabricantes, não apresentam sua eficiência apropriadamente descrita pelo método prescritivo. A alternativa 6 é um exemplo desse caso, cujo FS de 0,20 não foi suficiente para compensar a grande área envidraçada de $60 \%$, se analisado pelo método prescritivo. O nível de eficiência da envoltória permaneceu como $\mathrm{E}$, independentemente de se usarem vidros de FS 0,87 , vidros simples de $3 \mathrm{~mm}$, e FS de 0,20 , vidros de elevado desempenho, em geral laminados e metalizados. A alternativa 6 é um caso típico em que o método da simulação é o mais indicado para descrever apropriadamente o desempenho do edifício, com potenciais para alcançar nível de eficiência A.

\section{Conclusão}

Este artigo apresentou as principais questões referentes ao desenvolvimento do método prescritivo do RTQ-C (BRASIL, 2009a) através da aplicação em um caso-base e em alternativas para a envoltória, para o sistema de iluminação e para o sistema de condicionamento de ar.

O método prescritivo viabiliza a determinação simplificada do nível de eficiência. Essas simplificações apresentam limitações indicadas ao longo do artigo. Entre as mais relevantes estão a necessidade de simular a ventilação natural, os limites de uso de diferentes volumetrias para análise da envoltória e a pequena precisão de vidros de elevado desempenho em grandes aberturas envidraçadas.

Mas o método apresenta um elevado potencial de análise para uma variedade de casos e medidas de conservação de energia, cujas combinações são incontáveis. Das 13 alternativas para um caso-base de edifício de escritórios em Florianópolis, obtiveram-se eficiências com nível A, mais eficiente, a nível $\mathrm{E}$, menos eficiente. Os níveis parciais da envoltória, iluminação e condicionamento de ar foram combinados por

\footnotetext{
${ }^{5}$ Como citado na introdução, esse tipo de limitação nas especificações técnicas tende a acabar com o acordo de cooperação técnica entre Procel e Abividro.
}

meio de pesos predefinidos e relações de áreas de ambientes condicionados, não condicionados e de permanência transitória.

Espera-se que as questões discutidas esclareçam a origem dos critérios adotados no desenvolvimento do RTQ-C, em especial para o método prescritivo e para a envoltória, e esclareçam o potencial de uso desse método, de acordo com as características do edifício a ser avaliado. Espera-se ainda que as limitações esclarecidas possam orientar o avaliador a considerar o uso da simulação quando o método prescritivo não apresentar os recursos de avaliação mais adequados, visto se tratar de uma avaliação mais simplificada, enquanto a simulação é uma avaliação global e com maiores recursos de modelagem.

\section{Referências}

\section{ASSOCIAÇÃO BRASILEIRA DE NORMAS}

TÉCNICAS. NBR 5413: iluminância de interiores.

Rio de Janeiro, 1992.

ASSOCIAÇÃO BRASILEIRA DE NORMAS

TÉCNICAS. NBR 15220: desempenho térmico de edificações. Rio de Janeiro, 2005.

ASSOCIAÇÃO BRASILEIRA DE NORMAS

TÉCNICAS. NBR 15575: edifícios habitacionais de até cinco pavimentos. Rio de Janeiro, 2008.

AMERICAN SOCIETY OF HEATING, REFRIGERATING AND AIR CONDITIONING ENGINEERS. Standard 90.1-1989: energy

standard for buildings except low-rise residential buildings. Atlanta, 1989.

AMERICAN SOCIETY OF HEATING, REFRIGERATING AND AIR CONDITIONING ENGINEERS. Standard 90.1-1999: energy standard for buildings except low-rise residential buildings. Atlanta, 1999.

AMERICAN SOCIETY OF HEATING, REFRIGERATING AND AIR CONDITIONING ENGINEERS. Standard 90.1-2004: energy standard for buildings except low-rise residential buildings. Atlanta, 2004.

AMERICAN SOCIETY OF HEATING, REFRIGERATING AND AIR CONDITIONING ENGINEERS. Standard 90.1-2007: energy standard for buildings except low-rise residential buildings. Atlanta, 2007.

AUSTRALIAN BUILDING CODES BOARD
(ABCB). What's New. Canberra, 2004.
Disponível em:
<http://www.abcb.gov.au/content/whatsnew/>.
Acesso em: 15 fev. 2004 .

(ABCB). What's New. Canberra, 2004.

<http://www.abcb.gov.au/content/whatsnew/>. Acesso em: 15 fev. 2004. 
BRASIL. Decreto n. 4.059, de 19 de dezembro de 2001. Regulamenta a Lei no 10.295 , de 17 de outubro de 2001, que dispõe sobre a Política Nacional de Conservação e Uso Racional de Energia, e dá outras providências. Brasília, DF, 2001a. Disponível em:

<http://www.mme.gov.br/ministerio/legislacao/dec retos/Decreto\%20n\%204.059-2001.html>. Acesso em: 17 mar. 2003.

BRASIL. Lei n. 10.295, de 17 de outubro de 2001. Dispõe sobre a Política Nacional de Conservação e Uso Racional de Energia. Brasília, DF, 2001b. Disponível em:

<http://www.inmetro.gov.br/qualidade/lei10295. pdf>. Acesso em: 17 mar. 2003.

BRASIL. Instituto Nacional de Metrologia, Normalização e Qualidade Industrial (INMETRO). Portaria 163, de 08 de junho de 2009.

Regulamento Técnico da Qualidade do Nível de Eficiência Energética de Edifícios Comerciais, de Serviços e Públicos. Rio de Janeiro, 2009a. Disponível em: <http://www.inmetro.gov.br/legislacao/rtac/pdf/RT AC001462.pdf>. Acesso em: 03 mar. 2009.

BRASIL. Instituto Nacional de Metrologia, Normalização e Qualidade Industrial (INMETRO). Portaria 185, de 22 de junho de 2009.

Regulamento de Avaliação da Conformidade do Nível de Eficiência Energética de Edifícios Comerciais, de Serviços e Públicos. Rio de Janeiro, 2009b. Disponível em:

<http://www.inmetro.gov.br/legislacao/rtac/pdf/RT AC001465.pdf>. Acesso em: 03 mar. 2009.

CARLO, J. C. Desenvolvimento de metodologia de avaliação da eficiência energética do envoltório de edificações não-residenciais. 2008. 196 f. Tese (Doutorado em Engenharia Civil) Centro Tecnológico, Universidade Federal de Santa Catarina, 2008.

CARLO, J. C.; GHISI, E.; LAMBERTS, R. Energy Efficiency Building Code of Salvador, Brazil. In: CONFERENCE ON PASSIVE LOW ENERGY ARCHITECTURE, 20., 2003, Santiago. Proceedings... Santiago: PLEA, 2003.

CARLO, J. C.; LAMBERTS, R. Development of envelope efficiency labels for commercial buildings: effect of different variables on electricity consumption. Energy and Buildings, Oxford, v. 40, p. 2002-2008, 2008.

CARLO, J. C.; LAMBERTS, R. O papel da volumetria no desempenho energetic da edificação. In: ENCONTRO NACIONAL DE CONFORTO NO AMBIENTE CONSTRUÍDO, 2007, Ouro Preto. Anais... Porto Alegre: ANTAC, 2007. p. 1019-1028.
CASALS, X. G. Analysis of building energy regulations and certification in Europe: their role, limitations and differences. Energy and Buildings, Oxford, v. 38, p. 381-392, 2006.

\section{COMMERCIAL BUILDINGS ENERGY} CONSUMPTION SURVEY (CBECS). Information on the Commercial Building Sector. Washington, DC, 2003. Disponível em: <http://www.eia.doe.gov/emeu/cbecs/contents.html>. Acesso em: 08 July 2003.

CHICHIERCHIO, L. C.; FROTA, A. B. Proposta para Abordagem e Organização do Estudo sobre Normalização Ligada ao Uso Racional de Energia e ao Conforto Térmico em Edificações. In:

ENCONTRO NACIONAL DE

NORMALIZAÇÃO LIGADA AO USO

RACIONAL DE ENERGIA E AO CONFORTO AMBIENTAL EM EDIFICAÇÕES, 1., 1991, Florianópolis. Anais... Florianópolis, 1991. p. 1725 .

CRAWLEY, D. B. et al. EnergyPlus: creating a new-generation building energy simulation. In: Energy and Buildings, Lausanne, v. 22, p. 319331, 2001.

\section{DIRECÇÃO GERAL DE ENERGIA. Eficiência Energética nos Edifícios, E4. Lisboa: Ogilvry \& Mather, 2002.}

EANG, L. S.; PRIYADARSINI R. Building energy efficiency labeling programme in Singapore. Energy Policy, v. 36, p. 3982-3992, 2008.

HONG, T. A close look at the China Design Standard for Energy Efficiency of Public Buildings. Energy and Buildings, Oxford, v. 41, p. 426-435, 2009.

LAMBERTS, R. Uso racional de energia em edificações. In: ENCONTRO NACIONAL DE NORMALIZAÇÃO LIGADA AO USO RACIONAL DE ENERGIA E AO CONFORTO AMBIENTAL EM EDIFICAÇÕES, 1., 1991, Florianópolis. Anais... Florianópolis, 1991.

OLOFSSON, T.; MEIER, A.; LAMBERTS, R. Rating the energy performance of buildings. International Journal of Low Energy and Sustainable Buildings, v. 3, 2004. Disponível em: <http://www.byv.kth.se/avd/byte/leas>. Acesso em: 17 July 2007.

PÉREZ-LOMBARD, L. et al. A review of benchmarking, rating and labelling concepts within the framework of building energy certification schemes. Energy and Buildings, Oxford, v. 41, p. 272-278, 2009. 
PORTUGAL. Ministério das Obras Públicas, Transportes e Comunicações. Decreto-lei n. 79, de 4 de abril de 2006. Aprova o regulamento dos Sistemas Energéticos de Climatização em Edifícios. Lisboa, 2006. Disponível em: $<$ http://www.ordemengenheiros.pt/Portals/0/DL79 _2006.pdf>. Acesso em: 15 jan. 2008.

PROCEL. Avaliação do Mercado de Eficiência Energética no Brasil: pesquisa na classe comercial AT: relatório técnico. Rio de Janeiro, 2008a. Disponível em: <www.procelinfo.com.br〉. Acesso em: 25 nov. 2009.

PROCEL. Avaliação do Mercado de Eficiência Energética no Brasil: pesquisa na classe de prédios públicos: relatório técnico. Rio de Janeiro, 2008b. Disponível em: 〈www.procelinfo.com.br>. Acesso em: 25 nov. 2009.

PROCEL. Manual para Aplicação dos Regulamentos: RTQ-C e RAC-C. Rio de Janeiro: Procel/Eletrobras, 2009. Disponível em: <http://www.labeee.ufsc.br/eletrobras/etiquetagem /downloads.php>. Acesso em: 25 nov. 2009.
REY, F. J.; VELASCO, E.; VARELA, F. Building Energy Analysis (BEA): a methodology to assess building energy labelling. Energy and Buildings, Oxford, v. 39, p. 709-716, 2007.

\section{SANTANA, M. V. Influência de Parâmetros} Construtivos no Consumo de Energia de Edifícios de Escritório Localizados em Florianópolis-SC. 2006. 182 f. Dissertação (Mestrado em Engenharia Civil) - Universidade Federal de Santa Catarina, Florianópolis, 2006.

STANKEVICIUS, V.; KARBAUSKAITE, J.; MONSTVILAS, E. The development of reference values for energy certification of buildings in Lithuania. Energy and Buildings, Oxford, v. 39, p. 284-288, 2007. 